\title{
An Adaptive Superintendent Induction Program
}

\author{
Jim Brandon ${ }^{1}$, Kent Donlevy ${ }^{1}$, Paulette Hanna ${ }^{2}$, Dianne Gereluk ${ }^{1}$, Peggy Patterson ${ }^{1} \&$ Kath Rhyason ${ }^{2}$ \\ ${ }^{1}$ University of Calgary, Canada \\ ${ }^{2}$ College of Alberta School Superintendents, Canada \\ Correspondence: Dr. J. Kent Donlevy, Office of Graduate Programs in Education, Faculty of Education, \\ University of Calgary, 2500 University Drive, N.W., Calgary, Alberta T2N 1N4, Canada.
}

\author{
Received: August 31, 2013 Accepted: October 16, 2013 Online Published: October 28, 2013 \\ doi:10.11114/jets.v2i1.259 URL: http://dx.doi.org/10.11114/jets.v2i1.259
}

\begin{abstract}
This study examined a recently established induction program for new superintendents in the Canadian province of Alberta over a three-year period. In keeping with principles of design-based research data were collected from a variety of sources from the 26 new superintendents and their 25 mentors to assess and adjust programming through three design research cycles. Data from surveys, focus groups, interviews, participant observations and participant reflections were analyzed at the end of each year, and the findings were used to adapt the next program iteration. Results from the study indicate that the transitions of educational leaders into new positions as superintendents are more likely to be successful though access to quality induction programs that feature the following five program components: (1) standards based design, (2) orientation, (3) trained mentorship, (4) like-group support, and (5) large-group support. Further, this research supports the development of such induction programs through reciprocal change processes characterized by informed design, dialogic adoption, implementation as learning, and meaningful outcomes.
\end{abstract}

Keywords: Induction, Superintendents, Design-Based

\section{Introduction}

This design-based study assessed the New Superintendent Induction Program (NSIP) established by the College of Alberta School Superintendents (CASS) in the fall of 2009. Our research examined the structures, practices and supports provided to the new superintendents in 26 Alberta school districts over a three-year period. Assessment results were used to adapt, adjust and improve the NSIP at the end of each year.

Two conceptualizations shaped the research: (1) reciprocal educational change and (2) research-informed leadership induction (Table 1). Our analysis of the recent literature on educational change processes indicated that initiatives are more likely to succeed when they contain elements of reciprocal education reform (rather than mandated or bottom up education reform). Elmore (2000) wrote about the importance of this idea:

Accountability must be a reciprocal process. For every increment of performance I demand of you, I have equal responsibility to provide you with the capacity to meet that expectation. Likewise, for every investment that you make in my skill and knowledge, I have the responsibility to demonstrate some new increment in performance. This is the principle of "reciprocal accountability for capacity". (p. 5)

Such reciprocal educational change initiatives involve both pressure and support and are characterized by four stages: (1) informed design, (2) dialogic adoption, (3) implementation as learning, and (4) meaningful outcomes (Brandon, 2005; Levin, 2001). In the first stage, reforms reflecting informed design try to achieve modest goals that have a real chance of leading to desirable student outcomes. These approaches to change are based on research or evidence of positive results in similar jurisdictions and are most often offered as a comprehensive and coherent set of proposals. In the second stage dialogic adoption strategies provide opportunities for public input and open debate through authentic consultation processes. In contrast to consultation processes that have minimal or no impact on the way in which a change initiative unfolds, authentic adoption processes actually yield modified and improved proposals as a consequence of stakeholder engagement. 
The third stage of reciprocal educational change is characterized by an implementation as learning perspective. An effective implementation plan provides ongoing support, capacity-building and formative assessment for those who are expected to translate intentions into practice. A learning orientation to implementation taps into motivation and heightens efficacy. Another indicator is that the process of implementation itself is used as a basis for ongoing learning about the innovation. Refinements to practice are made in the field based on the actual implementation experiences. In the final analysis educational changes should be judged on the degree to which they achieve meaningful outcomes.

In keeping with these processes of reciprocal educational change, it follows that the content design of an induction program for new superintendents should be informed by the extensive body of research in the areas of leadership induction and development (Brandon, Morrow, Rhyason, \& Schmold, 2010; Couvier, Brandon, \& Prasow, 2006; Elmore \& Burney, 2000; Hargreaves, \& Fink, 2006; Lewis \& Murphy, 2008; Lipton \& Wellman, 2003). This research suggests a five component program: (1) standards based design, (2) orientation, (3) trained mentorship, (4) like-group support and (5) large-group support.

Table 1. The Two Frames Used in this Study

\begin{tabular}{ll}
\hline Reciprocal Educational Change & Research Informed Leadership Induction \\
\hline Informed Design & Standards Based Design \\
Dialogic Adoption & Orientation \\
Implementation as Learning & Trained Mentorship \\
Meaningful Outcomes & Like Group Support \\
& Large Group Support \\
\hline
\end{tabular}

Following a brief overview of our approach to design-based research in the methods section, we then describe NSIP activities and present assessment findings in each of the first three phases of this educational change initiative: design, adoption and implementation. Since the design and adoption phases were relatively short, the implementation phase is describe in considerably greater detail. Key events and features in each of the three implementation years are conveyed. New and mentor superintendent reflections are shared. Findings and program adaptations are outlined. Discussion of six meaningful outcomes and major lessons learned over the three-year course of the research precedes our concluding section.

\section{Methods}

\subsection{Design-Based Research}

Designed-based research is a methodological approach that studies an innovation as it is being implemented, refined and adjusted based on the interpretation of emergent data (Dai, 2012). The NSIP is the innovation examined in this case. Our three-year design-based study was philosophically grounded on pragmatic knowledge claims (Creswell, 2012) and the research iwasinformed by a variety of sources (Creswell, 2012; Dai, 2012; Kelly; 2012; Miles, Huberman, Saldana, 2014). Data analysis strategies were iterative and "endlessly creative and interpretive" as described by Denzin and Lincoln:

The researcher first creates a field text consisting of field notes and documents from the field .. . The writer-as-interpreter moves from this text to a research text: notes and interpretations based on the field text. This text is then re-created as a working interpretive document that contains the writer's initial attempts to make sense of what he or she has learned. Finally the writer produces the public text that comes to the reader... The interpretive practice of making sense of one's findings is both artistic and political. (2000, p. 23)

Sense-making involved the concurrent collection and analysis of data from multiple sources. Evidence summaries were read, highlighted and then re-read. Preliminary thoughts evolved to tentative themes, which were then solidified and tested through second and third reviews. Findings were generated through the systematic application of reasoned judgement, reflecting Meier's (2002) notion that sound interpretive systems "combine careful expertise, public evidence and eventual reliance on human judgment" (p. 198).

\subsection{Data Sources}

Qualitative data were gathered from six sources over the three years. An informal online survey was administered at the conclusion of the first year, 2009-2010. During each of the first two years semi-structured interviews were conducted. Several of the 26 superintendents who participated in induction program submitted written reflections at the end of each program year. Short, informal focus group interviews of the superintendents 
who attended each session took place at the end of program sessions during the first two years. Program documents were reviewed and participant observations from three of the authors were collected. Evidence from these sources was analyzed and applied with four questions in mind:

1. To what degree is the CASS New Superintendent Induction Program research informed?

2. What is working well in the program?

3. What could be done more effectively?

4. In what ways can the program be refined through ongoing assessment?

Data collected from all six sources were analyzed and then used to assess and to improve the program. A simple open-ended email survey administerd at the end of the first year gathered participant insights into what worked and what could have worked better in the first iteration of the program. All eleven participants responded and changes were implemented in the 2010-2011 program. Similarly, interviews and focus groups conducted in the first two years were based on the same two questions. Comments were noted, sumarized and shared with participants for accuracy checking. Again, the primary purpose was to assess the effectiveness of the program and to make improvements during the following year. The same approach was used as we analyzed many of the documents used in the progarm and in our anlysis of particpant observations from three of the researchers who actively participated in many of the induction sessions.

\section{Results}

Attention now turns to the results of our research, which are presented within three of the four phases of reciprocal change detailed in the Introduction. Program activities in Phases One (design) and Two (adoption) are itemized in the first sub-section. Assessment findings and analysis are then presented in the same sub-section. The remainder of the results portion of this paper is devoted to a more detailed treatment of the implementation phase of the educational change. The implementation phase is further divided into sub-sections for each of three school-years during which we studied the program.

\subsection{Design and Adoption Phases of the CASS New Superintendent Induction Program}

Though the CASS New Superintendent Program did not get underway until the fall of 2009, the seeds of its origin were sewn during the process culminating in the Alberta Commission on Learning Report (ACOL) in 2003. Recommendation 79 pointed to the need to

Develop a comprehensive, targeted program for preparing superintendents and providing ongoing professional development to support them in their role as CEO's of school jurisdictions. (Alberta Commission on Learning, 2003)

In preparation for implementing the ACOL recommendation, CASS commissioned two research papers (Gunderson, 2004; Lorenz, 2005), which laid the foundations upon which the program was established. It was not until the spring of 2009 that the Alberta superintendent's organization was in a position to act upon the ideas outlined in the two papers. As one condition of government funding for the second cycle of the CASS's leadership capacity building initiative, Moving and Improving, the development of an induction program for new superintendents was identified as a deliverable. By mid September of the same year, 10 novice superintendents and their mentors convened the inaugural CASS induction cohort learning session over dinner in an Edmonton hotel.

The program that emerged relied on multiple sources for its design blueprint. In addition to the Gunderson (2004) and Lorenz (2005) papers, a number of recent induction studies were consulted (Couvier, Brandon, \& Prasow, 2006; Elmore \&Burney, 2000; Hargreaves, \& Fink, 2006; Lewis \& Murphy, 2008; Leithwood, 2008; Lipton \& Wellman, 2003). Lessons learned from district level induction programs for teachers and school leaders were also applied. Though timelines were too short for mentorship training in the first year of the program, it was determined that the expertise, sophistication and experience of the superintendents selected to serve as NSIP mentors provided a sound rationale to move forward.

Over the following two years, all five of the elements of research-informed leadership induction programming identified in Table 1 in the Introduction were adopted and then implemented. Colleague mentors were trained to support novices. Cohort learning was based in part on the CASS Practice Standard (Lorenz, 2008) to which superintendents were held accountable. The chief additional curriculum source was the CASS Framework for School System Success (Morrow \& Schmold, 2009). An extensive orientation program based on the curriculum developed from the two documents was also established. 
The evidence in this section leads to three assessment claims. First, as outlined in Table 2 and 3 below, the NSIP origin and adoption processes can be characterized as informed design and dialogic adoption. The collaborative processes that were used to develop the program are exemplars of two important aspects of reciprocal educational change.

Table 2. Educational Change Standard: Informed Design

\begin{tabular}{ll}
\hline Assessment & Indicators \\
\hline Yes & $\begin{array}{l}\text { Pursues modest goals that are clearly focussed on elements that have a real chance of } \\
\text { leading to desirable outcomes. }\end{array}$ \\
Yes & $\begin{array}{l}\text { Is based on research or evidence of positive results in similar jurisdictions through } \\
\text { policy learning. }\end{array}$ \\
Partially & Initiates changes on the basis of a comprehensive and coherent approach \\
Yes & Matches proposals to their political and social contexts \\
\hline
\end{tabular}

Table 3. Educational Change Standard: Dialogic Adoption

\begin{tabular}{ll}
\hline Assessment & Indicators \\
\hline Yes & Provides opportunities for input and open debate through authentic consultation \\
& processes. \\
Yes & Yields modified and improved proposals through stakeholder consultation, \\
& collaboration or partnering.
\end{tabular}

The evidence further indicated that all five research founded induction programming elements were evident in the designed and adopted NSIP as reflected in Table 4 below.

Table 4. Research Informed Induction Programming

\begin{tabular}{ll}
\hline Assessment & Content Elements \\
\hline Yes & Standards Based Design \\
Yes & Orientation \\
In most cases & Trained Mentorship \\
Yes & Like Group Support \\
Yes & Large Group Support \\
\hline
\end{tabular}

\subsection{Implementation of the CASS New Superintendent Induction Program}

The 2011-2012 iteration of the CASS New Superintendent Induction Programs benefited from the application of research derived program learning during the first two years. This section begins with a review of the basic features of the 2011-2012 NSIP. We then highlight the key program elements in each year and share mentor and new superintendent reflections on their induction experiences.

The 2011-2012 incarnation of the NSIP linked each new superintendent with an experienced colleague who was trained as a mentor. In addition to these one-to-one connections, novices and mentors were provided with opportunities to actively engage in four half-day cohort sessions over the year. Some cohort sessions were scheduled with other superintendent association events and all sessions were made available to cohort participants across the province through video conferencing. Induction program content was based on the four major themes blended from key ideas from CASS Practice Standard and the Framework for School System Success. Along with other new central office leaders, beginning superintendents participated in an evening and a day and a half orientation that focused on these four major themes from the Practice Standard and the Framework. One distinct feature of the cohort and orientation learning was the fact that one or more practicing or recently retired CASS colleagues led each session.

\subsection{9-2010 Implementation}

The steps taken to get the NSIP up and running in August and September of 2009 reflected all three of the CASS Moving and Improving pillars: leadership, research and, most notably, "a bias for action" (Brandon, 2008). Through informal conversations with new superintendents and prospective mentors during the CASS Zone Summer Conferences all ten mentor-novice pairings were established. The notion of bringing new superintendents and mentors together for four half day cohort sessions was discussed and agreed to in a first 
evening session that was scheduled to coincide with a special meeting of all CASS members on the following day in the provincial capital.

Two fundamentals of the program emerged in the inaugural session. First, a great deal of care was taken to develop a set of group commitments that emphasized open and confidential sharing of leadership practice. Second, it quickly became clear that cohort sessions could provide valuable forums for deep learning about important (and previously underexplored) areas of practice with and from all participants (novices as well as mentors).

Three other important program components were developed and implemented during the 2009-2010 year. First, the CASS Summer Academy was planned and delivered in early July by four of the 10 first year mentors. The program focused on the four major themes: Vision and Direction Setting; Capacity Building; Relationships; and Managing the Knowledge Organization, blended from CASS Practice Standard and the Framework for School System Success. While the location and program content were positively reviewed, the summer timeframe was seen to be problematic. Second, two of the mentors were contracted to work with a consultant to develop a mentorship training session for delivery early in Year Two. Third, members of the CASS leadership team worked with the consultant to develop a CASS Induction Program Handbook to support mentor training and new superintendent orientation.

The overall response to the first year of the program was positive. Session evaluations, participant reflections, and an informal online survey generated four major insights that were subsequently translated into the program adaptions noted in Table 5 below. The written reflections of a 2009-2010 mentor are instructive.

As an experienced superintendent of more than ten years it was my pleasure to be asked, by CASS, to serve as a mentor for a new superintendent. It was clear that CASS was purposeful in its selection of mentors based upon experience, demographics and potential relationships. The benefits to new superintendents were both in having a formal mentor, but also in being part of a cohort of "newbies" who could compare their successes and challenges and come to understand the complexities of the position and the need for the broad support provided within CASS. (Mentor 1, March1, 2012)

A sample reflection from a 2009-2010 new superintendent participant is illustrative of the assessment data used to guide program adaptions after Year One.

Not only did it provide me with direct access to someone committed to support my development as a superintendent, it connected me to a network of other beginners who were wrestling with similar problems as well as to a larger group of experienced superintendents all of whom were there because they were committed to helping and supporting us as we learned to navigate the world of the superintendency.

Perhaps the one suggestion I would have for improvement would be that the program might have benefitted from a bit more structure around expectations on both sides of the relationship along with some "must address" topics since, a couple of times, I found that I did not know what I did not know until I needed to know it. (New Superintendent 1, March 16)

Additional assessment insights were provided by participants through the informal open-ended online survey administered in the spring of 2010. While most of the comments conveyed support for the program, several suggestions were also advanced. Four of these are noted below.

- The mentor selection process could have been better. I would like to have had a voice in choosing my mentor. My mentor was great by the way

- The mentoring part didn't work that well. I wasn't able to meet with my mentor very often.

- I loved the whole group gatherings because of the non-threatening environment. It was great to share and see what others were dealing with. I didn't get together enough with my mentor, but that's our fault not CASS's.

- I would like to have talked more about CEO-Board relations.

Table 5 summarizes the assessment findings for the 2009-2010 implementation year. What was learned from the first year of implementation in year one is presented in the left column. The design adaptations made to the program on the basis of these findings are presented in learning the right column.

Table 5. Implementation Year One Findings - Year Two Adaptations 


\section{Through our research we learned that \\ - Cohort sessions \\ - Were open, collaborative and useful. \\ - Benefitted mentors and novices. \\ - Were strengthened by standard specific, practitioner led presentations and conversations.}

- While participants appreciated the program supports, time to participate was an issue.

- Additional mentor capacity was needed.

- Mentoring relationships were more effective when

- The colleagues had some form of previous professional relationship.

- Their district offices were reasonably close to each other.

- A more in-depth orientation would be beneficial.
As we moved forward we

- Continued to employ these approaches.
- Continued with the program, but began to use video conferencing more frequently.

- Developed and implemented a mentor training program.

- Added level 2 support for those requiring additional assistance.

- Strived to provide more opportunities for novices to be involved in selecting their mentors.

- Tried to ensure participant district offices were reasonably close to each other.

- Expanded our one-day fall orientation to a 2 and a half day standards based summer academy.

\subsection{0-2011 Implementation}

Each new superintendent in the 2010-2011 school year was invited to participate in a telephone interview with a contracted research consultant during the summer of 2011. The following three questions were distributed in advance and were addressed in each interview:

1. In what ways did the NSIP help you as a beginning superintendent?

2. What could CASS have done to better support your practice as a beginning superintendent?

3. What other comments would you like to make about your transition into the position of Superintendent of Schools?

Several themes emerged from these conversations. Responses to Question One made it clear that new superintendents found the program to be beneficial. Responses further indicated that the cohort meetings were, perhaps the most valuable component of the program. Most respondents found their relationship with their mentor to be effective as well. Two respondents spoke to the importance of mentor selection to ensure that their mentors were good fits for them.

Two themes emerged in response to Question Two. Several respondents spoke to the necessity of gaining more clarity around the learning associated with superintendent to school board relations. The complexities of this area of practice caught many by surprise. Even more support would have been appreciated. Secondly, the issue of superintendent contract development was cited as a concern by several respondents. It was suggested that CASS could play a stronger role in this respect.

Responses to Question Three also centred on superintendent to school board relations. The politics of the superintendency emerged as a central point of discussion throughout the interviews. Superintendent evaluation practices were flagged as an issue by one respondent as an area worthy of more support from CASS. Two respondents expressed surprise at the intensity of the immediate pressures and the constant political demands of their new work as the chief executive officers of their school systems. Related to this emerging understanding was the realization that the new position kept them more distant from many of the operational leadership activities that had previously served as sources of accomplishment for them.

The overall response to the second year of the program was favourable. Session evaluations, participant reflections, and an informal online survey generated further insights that were subsequently translated into the program adaptations noted in Table 6. An excerpt from the reflections of one 2010-2011 mentor are provided.

Despite the fact that the new superintendents were in their first year, they did possess a wealth of experience and this enabled me to ask questions of them; therefore the relationship was very much a two-way sharing of information and practices. (Mentor 2, February 22, 2012)

The following excerpt form a 2010-2011new superintendent's reflections are illustrative of participant views 
Assuming the position of chief superintendent brings a host of new responsibilities and experiences. These include such things as working with an elected Board of Trustees, leading the senior leadership team, setting and protecting the vision for the school jurisdiction, working through principals to accomplish the goals of the jurisdiction and coming to understand all aspects of the operations of a multi-million dollar enterprise. No matter what other position an individual may have held in a school jurisdiction, there is little that truly prepares you to take on this challenging role.

The CASS superintendent mentorship program provided support as I began my role as a new superintendent. The opportunity to have a "lifeline" to an experienced superintendent was invaluable. There are situations that arise where everyone looks to the superintendent for guidance or decision-making. It is not always possible for a new superintendent to seek advice on all matters from other senior leaders or school board trustees. The option of phoning a mentor in the same role to seek advice on various matters certainly made me a stronger and more effective superintendent in my first year.

An improvement to the mentorship program would be seeking input from the protégé on potential mentors. Mentors were assigned to protégés in the CASS mentorship program. Since this relationship is intended to be close, personal and supportive, the needs of the protégé need to be considered when selecting a mentor. A more collaborative approach to selecting the mentor would provide the protégé with input and a sense of ownership of the relationship. (New Superintendent 2, February 14, 2012)

The following assessment table summarizes what we learned from the second year of implementation in the left column and the design adaptations made to the program on the basis of our learning in the right column.

Table 6. Implementation as Learning Year Two Findings - Year Three Adaptations

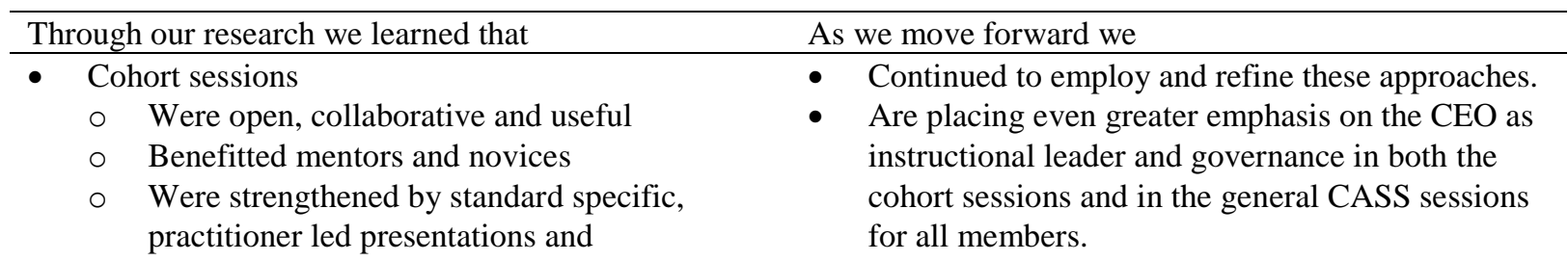

conversations.

- Should place even greater emphasis on the

ceo as instructional leader and school board governance

- Making time to participate continued to be a challenge.

- Mentoring relationships were not as successful in a few cases.

- Began to use video conferencing as the primary approach for most of the cohort sessions.

- Consistently involved novices in selecting their mentors.

- Began to provide more deliberate ongoing support to the program by regularly "checking in" with mentors and novices.

- Members appreciated the 3-day standards based summer academy, but were concerned about the

- Moved to an evening, one day and a half fall academy in Edmonton. summer timing and Banff location.

\subsection{1-2012 Implementation}

The third year of this program saw a change in leadership with the appointment of a new director of leadership learning (DLL). The new director used the findings from Year Two to implement program adaptations that continued to move the program forward. The new mentor-novice pairings were established by mid-August allowing each pairing to meet informally to set up regular scheduled times to meet one-to-one throughout the year either by phone or face to face. A schedule for the four 2011-2012 cohort sessions was developed and distributed to all cohort members.

New superintendents, along with other new central office leaders, participated in an evening and day and a half Orientation Academy in late September. Practicing and recently retired CASS colleagues led this introductory session. The location and program content was positively reviewed and all participants expressed appreciation for holding this event in the fall rather than the summer (as was the case in the previous year). 
Agendas for the four cohort sessions were developed in consultation with the mentors and new superintendents. Agenda topics continued to be structured around the four major themes blended from CASS Practice Standard and the Framework for School System Success. Board governance appeared on each session agenda. All sessions continued to focus on open communication and collaborative support while allowing confidential sharing of practice and information. The trusting and supportive environment of the cohort sessions allowed new superintendents to bring forward emergent problems and concerns for discussion and problem solving. The professional dialogue around these authentic problems was robust and created a learning opportunity for both mentors and new superintendents.

Those attending the cohort sessions through video conferencing did not appear to be hampered by the technology. All videoconference participants remained as engaged in the sessions as those attending face to face. Video conferencing had by this point become much more familiar to participants, who were observed to be quite comfortable interacting through this technology.

At the conclusion of the third year of the program the signs continued to be positive. Session evaluations, participant reflections and participant observations generated further insights that were subsequently translated into program adaptations. Below are the reflections of one 2011-2012 mentor.

I find being a mentor is more about listening and learning than it is about giving advice, my protégés are accomplished educators who simply haven't occupied the superintendent chair as long as I have. Each experience and scenario that is discussed causes me to reflect on my own practice and problem solving resulting in me being more effective. I hope that I am providing a parallel experience for my protégé.

I have found that predetermining meeting times in my second mentorship has been more beneficial than periodic or as needed meetings for they provide more continuity and flow to our conversations. Predetermined meetings also afford the opportunity to provide work plan timelines and forecasting of upcoming events and annual milestones. (Mentor 3, February 12, 2012)

The following excerpt from a 2011-2012 new superintendent provides additional insights about the induction program's benefits.

Another important component of this induction program was the opportunity to dialogue, ask questions, and seek guidance in a safe and secure environment. Many delicate and intricate situations were discussed during our various meetings and these conversations could not have occurred if a trusting and supportive environment did not exist. The establishment of this type of climate was integral to the success of this program.

If I could offer one suggestion for the implementation of future induction programs it would be to strive to create a roadmap or template of items or issues that new superintendents will be confronted with during their first year. (New Superintendent 3, February 14, 2012)

\subsection{Overall Assessment: Implementation 2009-2012}

The assessment evidence in the foregoing three sub-sections is outlined in Tables 4, 5 and 6 above. In each of the first three years of the CASS New Superintendent Induction Program, findings from design-based research were utilized to adapt the program to better meet the expressed needs of new superintendents in keeping with the principles of reciprocal educational change. As Table 7 below indicates, the implementation of the NSIP met the educational change standard of Implementation as Learning.

Table 7. Educational Change Standard: Implementation as Learning

\begin{tabular}{ll}
\hline Assessment & Indicators \\
\hline Yes & Taps into motivation and heightens efficacy. \\
Yes & $\begin{array}{l}\text { Provides ongoing support and capacity-building in the work setting for those } \\
\text { expected to translate reform intentions into practice. }\end{array}$ \\
Yes & $\begin{array}{l}\text { Is viewed as ongoing learning and an opportunity for refining practices based on } \\
\text { actual experiences in the field. }\end{array}$ \\
\hline
\end{tabular}

\section{Discussion}

At the core of the CASS New Superintendent Induction Program is the notion of evidence informed practice through the "artful" and intentional union of experience, judgement and expertise with the best available research evidence. These approaches tie well to recent research findings that educational change initiatives enhance their chances of success when they conceive of implementation as an ongoing learning and improvement process (Fullan, 
2010a, 2010b; Brandon, 2005). Rather than getting everything perfect from the beginning, change agendas are better served by action-oriented approaches that adapt, adjust and build support as they unfold.

The NSIP is a good example of an initiative with an implementation as learning theory of action. Three years into the program, the evidence presented in this study indicated that the following six meaningful outcomes were achieved.

1. The superintendents' association's theory of action - leadership research in action (Brandon, 2008) was realized through the application of the CASS Practice Standard and the CASS Framework for School System Success as the curriculum for new superintendents. The fall orientation and ongoing cohort learning sessions used material from these documents to deepen understanding of leadership practices that positively influence student learning. Participants learned with and from one another through dialogue, presentations and shared problem solving with respect to authentic issues and meaningful practice related scenarios.

2. New superintendents appreciated the support provided by more experienced colleagues trained in the mentoring process. At least three factors contributed to success in these relationships: committing to a regular communication schedule, relatively close geographic proximity and mentee participation in the selection of the mentor.

3. Both mentors and new superintendents reported they benefited from the open and collaborative consideration of important aspects of their practice through the cohort learning sessions. This finding is reflective of a more wide spread evolution in the visibility and de-privatization of superintendent practice.

4. This new generation of Alberta superintendents were building strengths in two important areas: instructional leadership and effective governance.

5. Induction programming was adapted to more fully integrate findings from this assessment conducted during each of the first three years of the program.

6. Twenty-five of the 26 superintendents who entered the program since 2009 continued in their positions and reported varying degrees of satisfaction with their new roles during the three years of this study. The non-continuing participant returned to his deputy superintendent position when the superintendent returned from a one-year leave as planned.

The importance of the leadership research in action approach to induction programming and the ongoing assessment for learning was underlined by the fact that 26 of the 62 Alberta superintendents were new to their positions at the conclusion of this three-year study. Moreover, when the number of mentors involved in the program (25) is taken into account, it means that 51 of the 62 then serving school superintendents had participated in the New Superintendent Induction Program. Eighty-three percent of the province's superintendents had been given the opportunity of deeply engaging in reflection and dialogue leading to the implementation of research informed district leadership practices proven to positively impact student learning

\section{Concluding Remarks}

This assessment makes two significant contributions to the fields of school district leadership and system improvement. On the process side, the study adds to our understanding of research informed approaches to educational change and system improvement. This study of the CASS New Superintendent Induction Program provides additional evidence that improvement efforts generated through processes of informed design, dialogic adoption, implementation as learning and meaningful outcomes are more likely to achieve their aims.

On the content side, our research into the NSIP offers insights into the development and sustainability of highly effective induction programs. The five research based components linked to successful superintendent induction in this study may have wider application to school leadership induction and, perhaps, for new teacher induction as well. This research adds weight to the claim that the transition of educators into new positions at any points in their careers are more likely to be successful though access to quality programs that feature the following five program components: (1) standards based design, (2) orientation, (3) trained mentorship, (4) like-group support and (5) large-group support.

\section{References}

Alberta Learning. (2003). Alberta's commission on learning. Every child learns. Every child succeeds. Report and recommendations. Edmonton, $\mathrm{AB}$ : Alberta Government.

Brandon, J. (2008). Moving and improving: Building system leadership capacity. Edmonton, AB: The College of Alberta School Superintendents. 
Brandon, J. (2005). A standards-based assessment of Alberta's teacher growth, supervision and evaluation policy. Unpublished doctoral dissertation, University of Calgary.

Brandon, J., Morrow, R., Rhysason, K., \& Schmold, S. (2010). Building superintendent capacity for school system success. Paper presented at the American Educational Research Association Annual Meeting, Denver.

Creswell, J. (2012). Educational research: Planning, conducting, and evaluating quantitative and qualitative research. Boston, MA: Pearson Education, Inc.

Couvier, S., Brandon, J., \& Prasow, C. (2006). Inhabiting a welcoming new landscape: A first year teacher's voyage of discovery. A Paper Presented to the International Conference on Teacher Education, Calgary, Alberta, November 4, 2006.

Dai, D. (2012). From smart person to smart design: Cultivating intellectual potential and promoting intellectual growth through design research. In D. Dai (Ed.), Design research on learning and thinking in educational settings: Enhancing intellectual growth and functioning (pp. 3-40). New York: Routledge.

Denzin, N., \& Lincoln, Y. (Eds.) (2000). Handbook of qualitative research. Thousand Oaks, CA: Sage Publishers.

Elmore, R. (2000). Building a new structure for school leadership. A policy paper prepared by The Albert Shanker Institute, Washington.

Elmore, R., \& Burney, B. (2000). Leadership and learning:Principal recruitment, induction and instructional leadershipin Community School District \#2, New York City. A paper provided by theHarvard Graduate School of Education.

Ely, M., Friedman, T., Garner, D., \& Steinmetz, A. (1997). Doing qualitative research: Circles within circles. New York: The Falmer Press.

Gunderson, T. (2004). Conceptual framework for a superintendency leadership formation program (Commissioned Paper). Edmonton, Alberta: College of Alberta School Superintendents.

Hargreaves, A., \& Fink, D. (2006). Sustainable leadership. San Francisco: Jossey-Bass.

Kelly, A. (2012). Developing validity and reliability criteria for assessments in innovation and design research studies. In D. Dai (Ed.), Design research on learning and thinking in educational settings: Enhancing intellectual growth and functioning (pp. 83-100). New York: Routledge.

Lancy, D. (1993). Interviewing informants. In Lancy, D (Ed.). Becoming qualitative researchers: An introduction (pp. 17-18). White Plains, NY: Longman.

Leithwood, K. (2008). Evidence-based characteristics of high performing school districts. Paper presented at the Moving and Improving Symposium, College of Alberta School Superintendents, Edmonton, AB.

Levin, B. (2001). Reforming education: From origins to outcomes. New York: RoutledgeFalmer.

Lewis, P., \& Murphy, R. (2008). Review of the Landscape: Leadership and leadership development: A review of what is known about effective leadership and leadership development. Nottingham, UK, National College for School Leadership,

Lipton, L., \& B. Wellman. (2003). Mentoring matters: A practical guide to learning-focused relationships. Sherman, CT: Mira Via.

Lorenz, L. (2005). An Induction program for the superintendency. Edmonton, AB: The College of Alberta School Superintendents.

Lorenz, L. (2008). CASS practice standard. Edmonton, AB: The College of Alberta School Superintendents.

Meier, D. (2002). Standardization versus standards. Phi Delta Kappan, 83(3), 190-198.

Miles, M., Huberman, A., \& Saldana, J. (2014). Qualitative data analysis. A methods sourcebook. Thousand Oakes, CA: Sage Publications.

Morrow, R., \& Schmold, S. (2009). A framework for school system success. Edmonton, AB: The College of Alberta School Superintendents.

\section{(c)) EY}

This work is licensed under a Creative Commons Attribution 3.0 License. 